\title{
Barcelona conmemora sus 90 años de dedicación al patrimonio arquitectónico local
}

En el marco de los actos de conmemoración del 90 aniversario de la creación, por parte de la Diputación de Barcelona, del Servicio de Catalogación y Conservación de Monumentos (SCCM, que hace casi dos décadas adoptó el nombre de Servicio del Patrimonio Arquitectónico Local SPAL), se celebró en esta ciudad, durante los días 21 a 23 de octubre de 2004, el Simposio Servicios de Monumentos, presente y futuro.

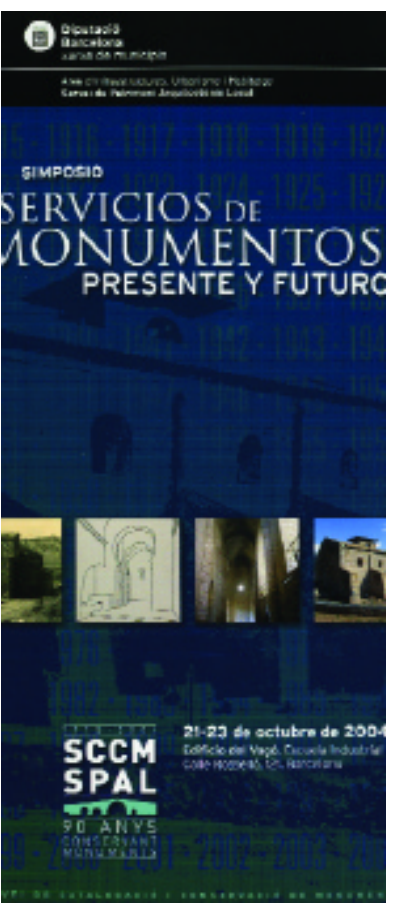

Desde un principio, la labor del SCCM (el más veterano de la geografía española) se basó en saber armonizar la práctica con la reflexión teórica sobre la intervención en los monumentos. El bagaje doctrinal y conceptual con que su primer director, el arquitecto Jeroni Martorell, se incorporó al mundo de la restauración se fue enriqueciendo y matizando después gracias al realismo y al pragmatismo a los que obliga la función pública, y al conjunto de circunstancias sociales y personales. Martorell basó la acción del Servicio en el rigor metodológico y en la diversidad de criterios, y este mismo espíritu ha guiado sus actuaciones y ha influido, directa o indirectamente, de modo decisivo en la manera de entender la restauración en nuestro país a lo largo de casi un siglo.

El Simposio, convocado por el SPAL, tuvo como objetivo reunir a representantes de otros servicios europeos que con el mismo cometido se han ido creando en los últimos veinte años, con el fin de reflexionar sobre cuáles han sido sus puntos de partida y su evolución, cuál la filosofía que ha regido en ellos, cuáles han sido los métodos y los criterios que se han aplicado en sus actuaciones en el patrimonio, con qué presupuestos han contado y cuáles han sido los resultados.

Diez fueron los servicios, todos ellos de la Administración pública, que se reunieron en el evento: además del SPAL (representado por su director, Antoni González, el arquitecto Josep Rovira y la historiadora Raquel Lacuesta), el Departamento de Arquitectura, Sección Urbanismo, del Ayuntamiento de Barcelona (arquitectos Maria Luisa Aguado y Josep M ${ }^{a}$ Julià); el Servicio de Patrimonio Histórico Arquitectónico de la Diputación Foral de Álava (arquitectos Juan Ignacio Lasagabaster y Macarena Ruiz); la Consejería de Cultura de la Junta de Andalucia (Carmen Ladrón de Guevara, jefa del Centro de Documentación del Instituto Andaluz del Patrimonio Histórico, y José Cuaresma, arquitecto y jefe del Servicio de Conservación y Obras del Patrimonio Histórico); el Servicio del Patrimonio Arquitectónico y Medioambiental de la Generalitat Valenciana (arquitectos Ricardo Sicluna e Ignacio Casar); el Servicio de Arquitectura de la Generalitat Valenciana (arquitecto Julián Esteban); el Servicio de Patrimoni Arquitectónico de la Generalitat de
Cataluña (arquitectos Antoni Navarro, Alfred Pastor y Esther Colls); la Soprintendenza per i Beni Architettonici e del paesaggio de Sassari e Nuoro, Cerdeña (arquitectos Stefano Gizzi, Rossella Isleño, Antonello Mons y Gianluca Zini); la Direcçao Geral dos Edificios e Monumentos Nacionais de Portugal (arquitectas Maria Fernández y Paula Silva); y el Instituto del Patrimonio Histórico Español del Ministerio de Cultura (arquitecto Ramón de la Mata).

El Simposio se desarrolló en tres sesiones, la primera de ellas dedicada a la explicación, por parte de sus representantes, sobre el funcionamiento de cada uno de estos organismos públicos, tanto desde el punto de vista de la praxis restauradora como de la organización, la gestión y los servicios que presta; la segunda se centró en la presentación de algunos proyectos y obras de restauración llevados a cabo por estos mismos organismos, y la tercera en la visita a dos monumentos catalanes en los que actualmente interviene el SPAL, guiada por el director de las obras, Antoni González, y por el arqueólogo Alberto López Mullor.

Las dos primeras sesiones concluyeron en sendas mesas redondas, en la que se pusieron de manifiesto los resultados globales obtenidos a través de la trayectoria que habían seguido estos servicios y se debatió el futuro de los mismos y, de manera especial, el futuro del patrimonio arquitectónico, a partir de la premisa planteada en la introducción del Simposio, sobre si corresponde a la Administración pública seguir protegiendo los monumentos, si ha de continuar haciéndolo como hasta ahora o si han de mejorar sus prestaciones y marcar la pauta sobre cómo se debería proteger de manera óptima el patrimonio que nos ha sido trasmitido, con qué recursos económicos, científicos y técnicos y con qué ideología de la intervención. Las respuestas a estas cuestiones fueron variadas y matizadas, pero los participantes concluyeron que la Administración pública ha de ser la responsable única de la protección y la actuación en el patrimonio, de establecer los criterios de intervención y de seguir ejerciendo una labor pedagógica con el fin de formar profesionales de la restauración monumental y de concienciar a la sociedad que administra o es administrada.

\section{Más información:}

Servicio del Patrimonio Arquitectónico Local

Correo-e.: s.patrimonial@diba.es

Raquel Lacuesta

SPAL 